\title{
A Simple and Portable Colorimeter Using a Red-Green-Blue Light-Emitting Diode and Its Application to the On-Site Determination of Nitrite and Iron in River-water
}

\author{
Yasutada Suzuki, ${ }^{\dagger}$ Terutomi Aruga, Hiroyuki Kuwahara, Miki Kitamura, Tetsuo Kuwabara, \\ Susumu KawaKUBo, and Masaaki IwATSUKI \\ Department of Applied Chemistry and Biotechnology, Interdisciplinary Graduate School of \\ Medicine and Engineering, University of Yamanashi 4-3-11, Takeda, Kofu, Yamanashi 400-8511, Japan
}

\begin{abstract}
A portable colorimeter using a red-green-blue light-emitting diode as a light source has been developed. An embedded controller sequentially turns emitters on and off, and acquires the signals detected by two photo diodes synchronized with their blinking. The controller calculates the absorbance and displays it on a liquid-crystal display. The whole system, including a $006 \mathrm{P}$ dry cell, is contained in a $100 \times 70 \times 50 \mathrm{~mm}$ aluminum case and its mass is $280 \mathrm{~g}$. This colorimeter was successfully applied to the on-site determination of nitrite and iron in river-water.
\end{abstract}

(Received March 9, 2004; Accepted April 19, 2004)

\section{Introduction}

Portable analytical instruments are important in many fields, such as environmental and clinical. Because samples in those fields are likely to change their properties, their analytical results should be obtained as soon as possible. If a portable instrument is used, the analysis can be done where the samples are taken.

Colorimeter-equipped light-emitting diodes (LEDs) as a light source compose one of such instruments. Actually, portable and battery-operated colorimeters are commercially available. ${ }^{1}$ Many researchers have developed LED-based systems not only for colorimeters, ${ }^{2,3}$ but also for the detectors of FIA ${ }^{4-6}$ and $\mathrm{CE}$, or fiber-optic sensors (optodes). ${ }^{8,9}$

In this work, we have developed a portable colorimeter that is compact and light $(100 \times 70 \times 50 \mathrm{~mm}$ in dimension and $280 \mathrm{~g}$ in mass). This colorimeter has a three-emitter LED (RGB, red, green and blue) as a light source and can measure the absorbance corresponding to each emitter, sequentially. Signal separation was done by a time-division technique that was widely used. 2,6,8,9

At first, the performance of the colorimeter was checked with several color dyes. After that, it was successfully applied to the on-site determination of nitrogen as nitrite in river-water, ${ }^{10}$ and the on-site determination of iron in river-water with the on-site extraction method using methylisobutylketone (MIBK). ${ }^{11,12}$

\section{Experimental}

\section{Electronics and optics}

A block diagram of the colorimeter is shown in Fig. 1. An

$\dagger$ To whom correspondence should be addressed.

E-mail: yamatori@ab11.yamanashi.ac.jp
RGB LED (Nichia TSTM515M) is used as a light source. The emission wavelength and the spectral band width (FWHM) of each emitter is as follows: red, 630 and 25; green, 525 and 45; blue, 470 and $30 \mathrm{~nm}$, respectively. An embedded controller (Renesas Technology H8/3664F, purchased from AkizukiDenshi as a board, AKI-H8/3664F) controlled all of the components in the colorimeter. A timing chart of the control sequence is shown in Fig. 2. Each emitter of the RGB LED was sequentially turned on and off by the controller, and the drive currents of the emitters were regulated by current regulator diodes (Ishizuka Electronics CRD E series); the values were 10, 15 and $8.2 \mathrm{~mA}$ for red, green and blue emitters, respectively. These values were determined experimentally so that the strength of the emission from each emitter could be as close as possible. Their light emissions were detected by two photodiodes (PD, Hamamatsu Photonics S2386-18K). One PD

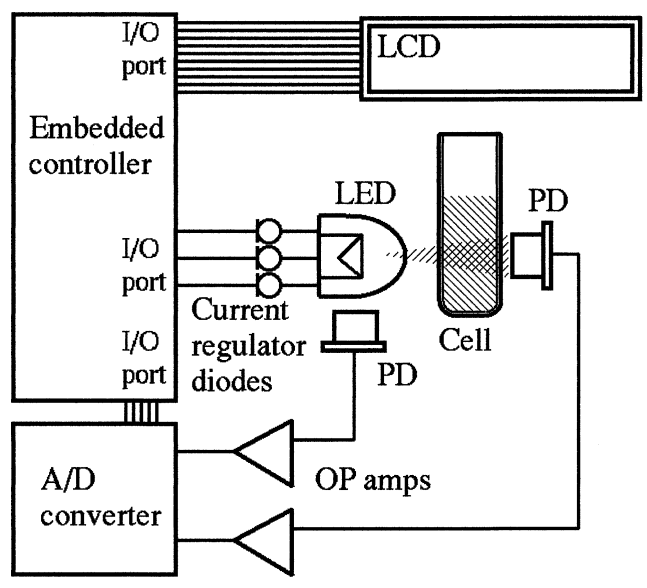

Fig. 1 Schematic diagram of the portable colorimeter. 


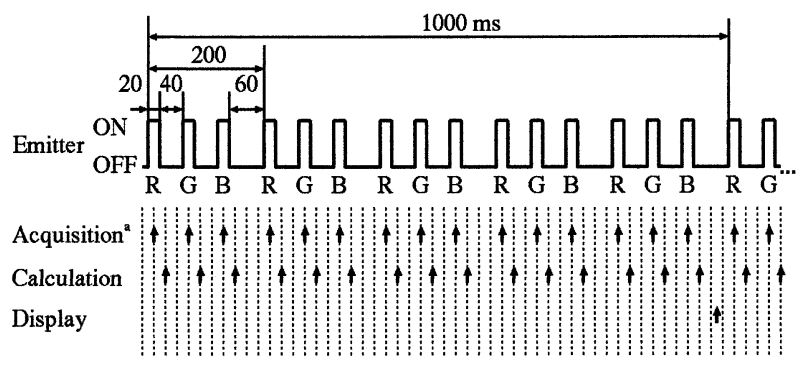

Fig. 2 Timing chart of the control sequence. a: Data acquisition was repeated 16 times and the result was averaged at each arrow.

was put behind a cell holder to detect the absorption by the sample solution, and another was put on the LED to correct for any fluctuation of the emission strength. The signals detected and amplified by operational amplifiers (New Japan Radio NJM2119D) were acquired by the controller through an analog-to-digital converter (A/D, Microchip MCP3204, 12 bit, 4 channels) synchronized with the blinking of emitters. The absorbance corresponding to each emitter was calculated, and was then displayed on a liquid-crystal display (LCD, Sunlike SC1602BS-B, 16 characters $\times 2$ lines).

\section{Software}

The software for the controller was written in Gnu C Compiler version 2.7.2.3 for $\mathrm{H} 8$ controllers running on the Linux.

\section{Reagents and samples}

All of the reagents used were of analytical grade. Deionized and distilled water was used throughout all of the experiments.

For nitrite determination, ${ }^{10}$ a sulfanilamide solution $(1 \%)$ was prepared by dissolving it with $10 \%$ hydrochloric acid. A naphthylethylenediamine solution $(0.1 \%)$ was prepared by dissolving it with water. River-water samples were collected from Fuefuki River and Nigori River, which flow in the south part of Kofu City, Yamanashi Prefecture, and were subjected to analysis without any processing.

For iron determination, ${ }^{12}$ a chelating reagent solution was prepared according to the following composition: $2.5 \mathrm{mmol}$ $\mathrm{dm}^{-3} 1,10$-phenanthroline- $1.0 \mathrm{~mol} \mathrm{dm}{ }^{-3}$ sodium thiocyanate- 0.1 mol dm${ }^{-3}$ hydrochloric acid. The samples were collected from Ai River, which flows in the north part of Kofu City. Three measurement points were selected, and were Fudo Bridge, Misaki Bridge, and Naka Bridge, respectively. Just after collection, they were filtrated with membrane filters (Advantec, LABODISC, 50CP045AN, pore size $0.45 \mu \mathrm{m}$ ) and acidified by hydrochloric acid to $0.1 \mathrm{~mol} \mathrm{dm}^{-3}$.

\section{Procedures}

On-site determination of nitrogen as nitrite. Basically, a previously described method was used. ${ }^{10}$ In a $20-\mathrm{cm}^{3}$ test tube with a ground-glass stopper, $10 \mathrm{~cm}^{3}$ of a river-water sample containing less than $150 \mu \mathrm{gN} \mathrm{dm}{ }^{-3}$ nitrite was taken. Then, 1 $\mathrm{cm}^{3}$ of $1 \%$ sulfanilamide was added and the tube was shaken. After $3 \mathrm{~min}, 1 \mathrm{~cm}^{3}$ of $0.1 \%$ naphthylethylenediamine was added and left for $20 \mathrm{~min}$ to produce a pinkish dye. The absorbance at $525 \mathrm{~nm}$ (Green emitter) was measured. In the previous work, measurement wavelength was $550 \mathrm{~nm}$, because LEDs used were different.

On-site determination of iron with on-site extraction. The procedure was described in detail elsewhere. ${ }^{12}$ To $20 \mathrm{~cm}^{3}$ of a
Table 1 Determination results of nitrogen as nitrite in riverwater samples $(n=6)$

\begin{tabular}{clccc}
\hline \multirow{2}{*}{ Date } & \multirow{2}{*}{ River $\begin{array}{c}\text { Dilution } \\
\text { factor }\end{array}$} & \multicolumn{2}{c}{ Found $/ \mu \mathrm{gN} \mathrm{dm}{ }^{-3}$} \\
\cline { 4 - 5 } & & & Colorimeter & Spectrophotometer \\
\hline $2001 / 8 / 31$ & Fuefuki & 1 & $12.7 \pm 0.5$ & $14.0 \pm 0.5$ \\
& Nigori & 5 & $135 \pm 3$ & $139 \pm 2$ \\
$2001 / 9 / 5$ & Fuefuki & 1 & $11.8 \pm 0.3^{\mathrm{a}}$ & $11.4 \pm 0.2$ \\
& Nigori & 2 & $116 \pm 2^{\mathrm{a}}$ & $109 \pm 2$ \\
\hline
\end{tabular}

a. On-site determination.

sample in a glass vial, $2 \mathrm{~cm}^{3}$ each of a chelating reagent solution and MIBK as extracting solvent was added and shaken. After obtaining a transparent MIBK phase, it was absorbed by a suction column filled with acrylic fibers. The extract was then ejected to a semi-micro glass cell by a micro-pipette. A dedicated holder was used to secure the position between the column and the vial or the cell during suction and ejection for easy operation in the field. The absorbance was measured at $525 \mathrm{~nm}$ against the MIBK reagent. For simplicity, a 2-point calibration ( 0 and $0.4 \mu \mathrm{g}$ iron) was used.

\section{Other apparatus}

For a comparative study, a conventional double-beam spectrophotometer (Shimadzu UV-200S) and a flame atomicabsorption spectrometer (FAAS, Hitachi 180-30) were used. The conditions for the latter were described elsewhere. ${ }^{12}$

\section{Results and Discussion}

\section{Performance evaluation with color dyes}

The performance of the colorimeter was validated with 3color dye solutions, such as Methylene Blue (MB), phloxine B $(\mathrm{PhB})$, and Methyl Orange (MO) for a red, a green, and a blue emitter, respectively. The formula of the obtained calibration curves, correlation coefficients, and linear range of concentration are as follows: $\mathrm{MB}, \mathrm{Abs}=4.97 \times 10^{-2}[\mathrm{MB} / \mu \mathrm{mol}$ $\left.\mathrm{dm}^{-3}\right]+5.8 \times 10^{-3}, r=0.9995,0-15 \mu \mathrm{mol} \mathrm{dm}{ }^{-3} ; \mathrm{PhB}, \mathrm{Abs}=$ $5.05 \times 10^{-2}\left[\mathrm{PhB} / \mu \mathrm{mol} \mathrm{dm}{ }^{-3}\right]+2.3 \times 10^{-3}, r=0.9991,0-5.4$ $\mu \mathrm{mol} \mathrm{dm}{ }^{-3} ; \mathrm{MO}, \mathrm{Abs}=2.89 \times 10^{-2}\left[\mathrm{MO} / \mu \mathrm{mol} \mathrm{dm}{ }^{-3}\right]-5 \times 10^{-4}$, $r=0.999_{9}, 0-20 \mu \mathrm{mol} \mathrm{dm}{ }^{-3}$. These results were compared with a double-beam spectrophotometer. The slopes of the curves obtained by the colorimeter were smaller and the linear ranges were narrower than the spectrophotometer. These are because the spectral bandwidths of the emitters are relatively wide, and the effect of stray light is large. The relative standard deviations of the measured absorbance were less than $4 \%(n=7)$, and we judged that it has enough performance for real applications.

\section{Determination of nitrogen as nitrite in river-water samples}

The calibration curves obtained with this colorimeter and the conventional spectrophotometer were $\mathrm{Abs}=2.70 \times 10^{-3}[\mathrm{~N} / \mu \mathrm{g}$ $\left.\mathrm{dm}^{-3}\right]+8.8 \times 10^{-3}, r=0.999_{9}$ and Abs $=4.57 \times 10^{-3}\left[\mathrm{~N} / \mu \mathrm{g} \mathrm{dm}^{-3}\right]$ $+4.8 \times 10^{-3}, r=0.999_{8}$, respectively. The relative standard deviation was less than $1 \%$ and the limit of detection was 0.7 $\mu \mathrm{gN} \mathrm{dm}{ }^{-3}$, which is calculated from $3 \sigma$ of the blank $(n=4)$. Although the slope of the calibration curve with the colorimeter was smaller than that of the spectrophotometer, the colorimeter had sufficient sensitivity for the determination of real samples. At first, the accuracy of the determination of nitrogen as nitrite in real samples by the colorimeter was checked by a comparison with those by the spectrophotometer. Then, an on-site analysis 
Table 2 Comparison of the results between the on-site determination of iron in river-water samples with this colorimeter and a determination in our laboratory with FAAS

\begin{tabular}{lccc}
\hline $\begin{array}{c}\text { Measurement } \\
\text { point }^{\mathrm{a}}\end{array}$ & $\begin{array}{c}\text { Found/ } \\
\mu \mathrm{g}\end{array}$ & $\begin{array}{c}\text { Conc./ } \\
\mu \mathrm{g} \mathrm{dm}^{-3}\end{array}$ & $\begin{array}{c}\text { FAAS/ } \\
\mu \mathrm{g} \mathrm{dm}\end{array}$ \\
\hline Fudo Bridge & $0.052,0.044$ & $2.6,2.2$ & $\mathrm{ND}$ \\
Misaki Bridge & $0.114,0.103$ & $5.7,5.1$ & $\mathrm{ND}$ \\
Naka Bridge & $0.378,0.389$ & $18.9,19.5$ & $34 \pm 5$ \\
Naka Bridge & $0.629,0.615$ & $31.4,30.8$ & $34 \pm 2$ \\
(after 24 h) & & & \\
\hline
\end{tabular}

ND: Not detected.

a. From upper to lower stream.

by the colorimeter was performed and its results were compared with the results by the spectrophotometer after samples being brought back to our laboratory within $3 \mathrm{~h}$. These results are listed in Table 1. They were in good agreement with each other.

Determination of iron in river-water samples with on-site extraction

The equation obtained by a 2-point calibration was $\mathrm{Abs}=$ $(0.221 \pm 0.036)[\mathrm{Fe} / \mu \mathrm{g}]+(0.004 \pm 0.001)(n=8)$. The limit of detection was $0.7 \mu \mathrm{gFe} \mathrm{dm}^{-3}$ ( $3 \sigma$ of blank). According to the literature, ${ }^{11}$ the interferences of $\mathrm{V}(\mathrm{V}), \mathrm{Ni}(\mathrm{II}), \mathrm{Cu}(\mathrm{II})$, and $\mathrm{W}(\mathrm{VI})$ were serious. However, it was found that they did not interfere up to 2.5-times the iron concentration. Because their concentrations in natural fresh water are generally less than that of iron, and are below $10 \mu \mathrm{g} \mathrm{dm}^{-3}$, there is no problem to apply this method to the determination of iron in river-water samples. The results of on-site determination are listed in Table 2. The concentrations of iron were found to be increasing from the upper to lower stream, which might be due to wastewater. Because the concentrations of Fudo Bridge and Misaki Bridge samples were below the detection limit of FAAS, the results could not be compared. On the other hand, the discrepancy of the results from Naka Bridge was fairy large. The sample after leaving for $24 \mathrm{~h}$ at $5^{\circ} \mathrm{C}$ was determined by both methods and the results were compared again. It was found that they were almost in agreement with each other. From this fact, it was assumed that about $40 \%$ of the iron in the sample from Naka Bridge was contained in fine particles smaller than $0.45 \mu \mathrm{m}$, and they gradually dissolved upon standing in a $0.1 \mathrm{~mol} \mathrm{dm}^{-3}$ acid solution for $24 \mathrm{~h}$. We think that this is not a fault, but is useful for speciation.

\section{Conclusions}

A portable colorimeter using an RGB LED as a light source has been developed. It was successfully applied to the on-site determination of nitrogen as nitrite and iron in river-water samples. Since it is portable and not so very expensive, it would be suitable not only for the on-site analysis of various samples, but also for education, such as student experiments or environmental education.

\section{Acknowledgements}

This work was supported in part by a grant from The Asahi Glass Foundation (No. 02A-C01-P054, to T. K. and Y. S.)

\section{References}

1. "Pocket Colorimeter II Analysis System", Literature No. 2441, 2003, Loveland, CO, HACH.

2. J. G. Schnable, P. J. Grochowski, L. Wilhelm, C. Harding, M. Kiefer, and R. S. Orr, Field. Anal. Chem. Tech., 1988, 2,21 .

3. K. Shimizu and K. Tenra, Kagaku to Kyoiku, 1991, 39, 566.

4. K. Higuchi, A. Inoue, H. Tamanouchi, T. Hattori, and S. Motomizu, Bunseki Kagaku, 1999, 48, 477.

5. S. Jambunathan, P. K. Dasgupta, D. K. Wolcott, G. D. Marshall, and D. C. Olson, Talanta, 1999, 50, 481.

6. J. Huang, H. Liu, A. Tan, J. Xu, and X. Zhao, Talanta, 1992, 39, 589.

7. M. King, B. Pauli, P. R. Haddad, and M. Macka, Analyst, 2002, 127, 1564.

8. R. R. Smardzewski, Talanta, 1988, 35, 95.

9. A. J. Guthrie, R. Narayanaswamy, and N. A. Welti, Talanta, 1988, 35, 157.

10. Y. Shimazaki, F. Fujioka, and M. Iwatsuki, Field. Anal. Chem. Tech., 1998, 2, 173 (Y. S.: Name changed after adoption in Jan. 2001 from Shimazaki to Suzuki).

11. V. P. R. Rao, K. V. Rao, and P. V. R. B. Sarma, Talanta, 1969, 16, 277.

12. S. Kawakubo, A. Naito, A. Fujihara, and M. Iwatsuki, Anal. Sci., in submitting. 